\title{
Coexistence of immune thrombocytopenic purpura and polycythemia vera
}

\author{
Didar Yanardag Acik* \\ Ministry of Health, Adana State Training and Research Hospital, Hematology and Internal Diseases Clinic, Adana, Turkey
}

\begin{abstract}
Polycythemia vera and immune thrombocytopenic purpura clinics are two different hematologic diseases in aspect of etiology and treatment. Coexistence of both diseases may cause difficulties in treatment method. There is very few source relating to treatment method and coexistence of polycythemia vera and immune thrombocytopenic purpura in literature. We have presented two cases with polycythemia vera and immune thrombocytopenic purpura and our treatment method.
\end{abstract}

Polycythemia Vera (PV) is a chronic, clonal and progressive myeloproliferative disease generally characterized by leukocytosis, thrombocytosis, splenomegaly accompanied by an increase in erythroid series. Proliferation appears in erythroid, myeloid and megakaryocytic series and bone marrow [1]. Diagnosis of PV often requires the presence of a JAK2 mutation, in addition to documentation of increased hemoglobin/hematocrit, to a threshold level established by the 2016 World Health Organization (WHO) revised criteria ( $>16.5$ $\mathrm{g} / \mathrm{dL} / 49 \%$ for males and $>16 \mathrm{~g} / \mathrm{dL} / 48 \%$ for females) [2]. Primary immune thrombocytopenia (ITP) is an acquired immune-mediated bleeding disorder characterized by autoantibody-mediated platelet destruction and impaired megakaryocyte maturation with reduced platelet production [3]. There is no certain clinical or laboratory finding for diagnosing ITP. Diagnosis is based on exclusion of other causes inducing thrombocytopenia [4]. Our treatment objective in PV is to suppress the increase of myeloid serial cells (erythrocyte, blood platelets, monocytes and granulocytes) primarily erythrocyte. On the contrary, our treatment target for ITP is to increase the number of blood platelets in peripheral blood. Therefore, coexistence of PV and ITP causes difficulties in treatment.

There is one source in literature relating to coexistence and treatment of these two diseases [5]. In our article, we have discussed two cases with coexisting PV and ITP and their treatment methods.

\section{Case 1}

49 years old, male patient was referred due to high $\mathrm{Hb}$ and low blood platelets. Patient had no chronic disease and drug using history. He had skin eruption in the form of nose bleeding and purpura, conjunctivas were hyperemic. In full blood count, results are $\mathrm{Hb} 17.3 \mathrm{gr} / \mathrm{dL}, \mathrm{Hct}$ \%51. PLT: $16,000 / \mu \mathrm{l}$, White blood cell (WBC): $9 \times 10^{3} / \mu \mathrm{l}$ and EPO: 6.46 $\mathrm{mU} / \mathrm{mL}$. JAK2 was positive. $1 \mathrm{mg} / \mathrm{kg} /$ day prednisolone was initiated for patient, 1 unit of phlebotomy was implemented. Blood platelet values are elevated under steroid treatment, however blood platelet values started dropping after lowering steroid dose at the end of 2 months. No splenectomy was planned for second step since the risk of thrombosis will increase in case of temporary thrombocytosis that may occur after splenectomy because ITP was accompanied with polycythemia. $50 \mathrm{mg} /$ day Eltrombopaq was initiated, during the controls performed 10 days later, PLT increased to $150,000 / \mu \mathrm{l}$, treatment continued with $25 \mathrm{mg} /$ day eltrombopaq and blood platelet level was around 47000-10000. No acetylsalicylic acid was implemented due to risk of hemorrhage. Phlebotomy was performed for 3 times during his 1year monitoring period and no complication such as hemorrhage or thrombosis was observed.

\section{Case 2}

25 years old, male patient was referred to hematology clinic with complaints of weakness, headache, itching and easy bruising on areas open for trauma. Patient had no history of chronic diseases, drug using and smoking. In full blood count, results were as hemoglobin $(\mathrm{Hb}) 16.9$ gr/dL, hematocrit (Hct)\%49.2, platelet (PLT) $92.000 / \mu l$, White blood cell (WBC): $14.6 \times 10^{3} / \mu \mathrm{l}$ eritropoetin (EPO) $4.9 \mathrm{mU} / \mathrm{mL}$. JAK2 was positive. Since PLT was over 30,000 and there was no evidence of active bleeding, treatment was not given to increase the platelet. Phlebotomy was performed due to reasons of Hct over \% 45, headache and itching complaints. No acetylsalicylic acid was implemented due to low level of blood platelets. Patient was monitored with intervals of 3 months. No complication was observed.

\section{Discussion}

Different hematologic diseases overlapping with each other were notified however coexistence of Polycythemia Vera and ITP has not been include to literature other than 3 cases .Pasquale Niscola, et al. have implemented steroid treatment and phlebotomy to patients with coexisting P. Vera and ITP in the article they presented; they have attempted to keep hct and blood platelet levels under safe limits by using that treatment.

*Correspondence to: Didar Yanardag Acik, Ministry of Health, Adana State Training and Research Hospital, Hematology and Internal Diseases Clinic, Adana, Turkey, E-mail: didaryanardag@gmail.com

Key words: polycythemia vera, immune thrombocytopenic purpura, treatment method

Received: April 19, 2019; Accepted: April 25, 2019; Published: April 29, 2019 
We have implemented phlebotomy together with steroid treatment to our first patient. However, we have ceased implementation of steroids after 2 since risk of thrombosis will increase with the side effects of steroid treatment and polycythemia. We used Eltrombopaq treatment instead of steroid; we have not observed any complication such as hemorrhage or thrombosis during our one year monitoring by using such treatment method.

We did not require steroid treatment for our other patient and monitored by only implementing phlebotomy.

We have presented two of our cases with coexisting P. Vera and ITP and treatment method in our article.

\section{References}

1. Spivak JL, Barosi G, Tognoni G, Barbui T, Finazzi G, et al. (2003) Chronic myeloproliferative disorders. Hematology Am Soc Hematol Educ Program. [Crossref]

2. Tefferi A (2018) Polycythemia vera treatment algorithm 2018. Blood Cancer Journal 8: 3.

3. Qu MM, Liu XN, Liu XG, Feng Q, Liu Y, et al. (2017) Cytokine changes in response to TPO receptor agonist treatment in primary immune thrombocytopenia. Cytokine 92 : 110-117. [Crossref]

4. Diz-Küçükkaya R, Chen J, Geddis A, Lopez JA (2010) Thrombocytopenia, (Chapter 119), Williams Hematology. (8th Edn) Lichtman MA, Beutler E, Kipps TJ, Selighson U, Kaushansky K, et al. (EDS) Mc Graw Hill Company, USA.

5. Pasquale Niscola, Marco Giovannini, Paolo de Fabritiis (2011) Idiopathic thrombocytopenic purpura coexisting with polycythemia vera. Asian J Transfus Sci 5: $187-188$.

Copyright: (C2019 Acik DY. This is an open-access article distributed under the terms of the Creative Commons Attribution License, which permits unrestricted use, distribution, and reproduction in any medium, provided the original author and source are credited. 